\title{
Regulierung und Privatrecht
}

\author{
Staatliche Verhaltenssteuerung mittels Privatrecht und ihre Bedeutung für \\ Rechtswissenschaft, Gesetzgebung und Rechtsanwendung
}

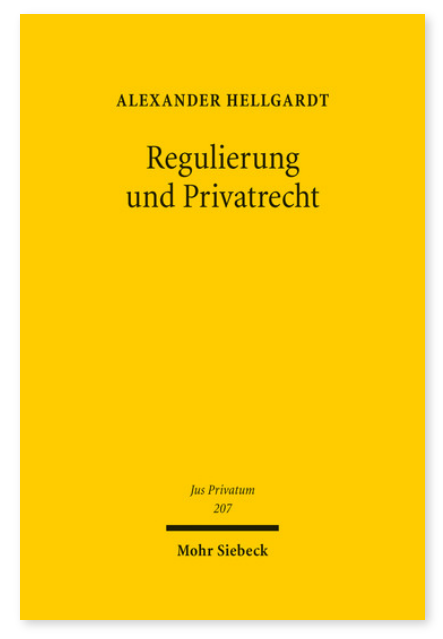

2016. XXXIV, 848 Seiten. JusPriv 207

ISBN 978-3-16-154368-5

DOI 10.1628/978-3-16-154368-5

eBook PDF 159,00€

ISBN 978-3-16-154339-5

Leinen $159,00 €$
Privatrecht ist ein Werkzeug des Gesetzgebers zur Regulierung von Wirtschaft und Gesellschaft. Ausgehend von dieser anhand des Kauf- und des Sachenrechts belegten These, legt Alexander Hellgardt eine umfassende Untersuchung des Einsatzes von Privatrecht zur Verhaltenssteuerung im öffentlichen Interesse vor. Er untersucht den unions- und verfassungsrechtlichen Rahmen der Regulierung mittels Privatrecht und entfaltet die Konsequenzen für Rechtswissenschaft, Gesetzgebung und Gerichtspraxis. Der Autor demonstriert, wie Privatrechtswissenschaft zu einer Regulierungswissenschaft werden kann, er entwickelt Kriterien, die den Gesetzgeber bei der Wahl von Regulierungsinstrumenten im Einzelfall anleiten können, und zeigt, wie die Rechtsanwendung die Regulierungsfunktion aufnehmen kann, indem die teleologische Auslegung um Elemente der Folgenabschätzung und Steuerung erweitert wird.

Alexander Hellgardt Geboren 1978; Studium der Rechtswissenschaft und Philosophie (B.A.) in Tübingen; wissenschaftlicher Assistent am Max-Planck-Institut für ausländisches und internationales Privatrecht in Hamburg; 2008 Promotion; 2008 Zweites Staatsexamen in Hamburg; Master-Studium an der Harvard Law School; seit 2009 wissenschaftlicher Referent am Max-Planck-Institut für Steuerrecht und Öffentliche Finanzen in München; 2015 Habilitation; im WS 2015/16 Lehrstuhlvertretung an der Ludwig-Maximilians-Universität München.
Jetzt bestellen:

https://mohrsiebeck.com/buch/regulierung-und-privatrecht-9783161543685?no_cache=1

order@mohrsiebeck.com

Telefon: +49 (0)7071-923-17

Telefax: +49(0)7071-51104 